\title{
Translation Studies Analysis under the Perspective of Intercultural Communication
}

\author{
Lu Wei \\ Jingdezhen Ceramic Institute, Jingdezhen, Jiangxi Province, China
}

Keywords: Exploration, Intercultural communication, Perspectives of translation, Translation studies

\begin{abstract}
This article expounds the relationship between culture and translation, and discusses the specific methods of translation in cross-cultural communication. In the process of translation, we should have a profound understanding of the cultural meaning of the original text, and adopt different methods of translation according to the specific context. The article enumerates and analyzes different translation methods and makes accurate explanations so that the translation can better promote the nationality Cultural exchange.
\end{abstract}

\section{Introduction}

"Cross-culture" was introduced to our country in the late 1980s. In the past 30 years of English teaching, most of the students have focused on college English education. Since the 1990s, the input of intercultural communication has really started Middle school English education. The goal of English education in our country has shifted from simple communicative competence of applied language skills to intercultural communicative competence [1]. The newly promulgated "New English Curriculum Standards" explicitly put forward and emphasized in addition to language skills, knowledge, emotional attitude, learning strategies other than cultural awareness. Visible students must pay attention to cultivating students' intercultural awareness at the same time that they should learn English and enable students to see western cultural knowledge through this point of teaching materials [1]. Whether it is basic knowledge of social norms, customs and practices, they can have a preliminary understanding of western countries, Form a face. At the same time, students will consciously compare Western culture with their own culture while also deepening their understanding and understanding of their own culture. Such students learn English in the context of understanding Western cultural knowledge, embracing the influence of exotic culture is an important foundation for cultivating students' intercultural communication skills.

"The biggest difficulty in translation is the difference between the two cultures, where there is something self-evident in one culture that has to be painstakingly explained in another culture. What we do not have to explain to our own readers, to foreign readers have to explain [1]. Therefore, it is of great significance and practical value to cultivate translators' awareness of transculturalism and to establish a cultural translation perspective both for translation theory and practice.

\section{Cross-cultural communication analysis}

The characteristics of cross-cultural communication: First, the diversity of culture, countries with different culture is formed in the process of communication, cross-cultural communication is based on the communication with different countries culture under the premise of; Second, with common linguistic, i. e. , is the people of different languages in order to achieve the purpose of communication, application of the same kind can accept language to communicate with each other; Third, using oral direct expression characteristics, people often suffer in cross-cultural communication in communication takes the form of oral expression, and is directly face each other in communication.

\subsection{Cross-cultural communication consciousness of the role of English teaching.}

The English name of "cross-cultural communication" is "cross - cultural communication (or Intel - 
cultural communication)". It refers to native speakers with the native language of communication between. It also refers to any in language and culture background differences of communication between people. Generally people think this refers to the native people in communicating with the native people should pay attention to because of the problems arising from different cultural background, how to communicate more smooth communication [2]. Cross-cultural communication ability is an important part of language communication ability, and cultivate the students' cross-cultural communicative competence is one of the tasks of college English teaching. "College English syllabus for college English teaching demand for cross-cultural communication ability training, think on cross-cultural communication teaching in college English teaching is necessary, the goal is to help students to solve in cross-cultural communication problems caused by cultural differences.

\subsection{The significance and necessity of intercultural communication.}

Actual intercultural communication refers to the: between people of different language as well as the national language communication activities. People with different cultural backgrounds to communicate, you must use the language tool to complete [2]. Due to different countries all have their unique language features and properties, therefore, in order to achieve the mutual communication, is familiar with the national culture, on the basis of fusion with the cultural background of language to communicate, to produce more good effect. So in college English teaching should focus on the cultivation of the intercultural communication and application aspects.

\section{Intercultural Communication and Translation}

Intercultural communication mainly refers to the communication between the native speakers and non-native speakers, as well as the communication between people who differ in any aspect of language or culture background. Due to the differences in surroundings, societies and religions of different ethnic groups, each language community results in its own code of language, social culture, customs and practices and so on. Intercultural communication studies situations when people from different culture backgrounds interact [3]. Aside from language, IC focuses on social attributes, thought patterns and the cultures of different groups of people. IC also involves understanding the different cultures, languages and customs of people from other countries. There are three formats of IC: interracial communication (when source and receiver are different races), interethnic communication (situation in which the parties are of the same race but of different ethnic origins) and intracultural communication (communication between members of the same culture including racial, ethnic and other co-cultures).

The term translation itself has several meanings: it can refer to the general subject field, the product (the text that has been translated) or the process (the act of producing the translation, otherwise known as translating). The process of translating between two different written languages involves the translator changing an original written text (the source text) in the original verbal language (the source language) into a written text (the target text) in a different verbal language (the target language) [3]. This type corresponds to "interlingual translation" and is one of the three Roman Jakobson in his seminal paper. Jakobson's categories are:

(1) Intralingual translation, or "rewording" - an interpretation of verbal signs by means of other signs of the same language;

(2) Interlingual translation, or "translation proper" - an interpretation of verbal signs by means of some other language;

(3) Intersemiotic translation, or "transmutation" - an interpretation of verbal signs by means of signs of non-verbal sign systems. Intralingual translation would occur when we rephrase an expression or text in the same language to explain or clarify something we might have said or written. Intersemiotic translation would occur if a written text were translated, for example, into music, film or painting. It is interlingual translation which is the traditional, although by no means exclusive, focus of translation studies.

It is easily seen that the three forms of intercultural communication and the three types of 
translation are partly corresponding to each other, especially interracial communication and interlingual translation which both attach attention on the communication between native and non-native, and where different cultures of different countries play more important role. To conduct effective intercultural communication, one has to understand the differences between the different nations and then to look for them and pay attention to in every cross-cultural communication situation [3]. By doing this, the high-context communicators can learn to use and respond words, emotions, postures differently, and low-context communicators can learn to pay attention to context and learn to interpret meaning in terms of the context. It is evident that different countries or nations have quite different customs, cultures, ways to express emotions and so on, to become successful communicator and avoid serious culture shock and failure, it's essential to have intercultural knowledge about low context, high context, power distance and other information, to eradicate stereotypes, to hold placid attitude, to know that cultures are different.

And there was no doubting translation is an intercultural activity. The culture of source text can only find echoes from source language readers, however, for target language readers, the lack of similar cultural background may lead to the loss of ingenuity of the originals. Translation as a tool of communication is thus a significant intercultural activity aiming at breaking the language and culture barriers and enriching communication [4]. To become a successful translator or interpreter, learning culture difference is an inevitable aspect of training. Translation texts are the product of the mutual influence of source language culture and target language culture. The properties, extent and concrete level of the two languages and cultures are to some degree influencing the choice of translation strategies, syntactic structures and words of the translators. Thus culture as a dispensable capability of a translator, of conducting effective translation makes translation resemble to intercultural communication.

Effective intercultural communication cannot be accomplished at one stroke, and it is impossible to do successful translation without knowledge of cultures. To stride across the cultural barriers of different nations, it's necessary to adjust the attitude of intercultural communication, and recognize the discrepancy of translation strategies, so to reconstruct the artistic sense of originals, and appeal to more target readers with vigorous translation. Knowing better the relationship between intercultural communication and translation is of great importance to these two practices.

\section{The cross-cultural translation methods}

We should have a profound understanding of the cultural connotations in the translation of culturally distinctive words, and adopt the following methods to achieve the purpose of interpreting the culture. Both English and Chinese have great differences in syntax, vocabulary and rhetoric. Therefore, they must encounter many difficulties in translating English into Chinese and need some translation skills to guide them [4]. Commonly used translation techniques include translation method, provincial translation method, conversion method, split sentence method, merge method, positive translation method, anti-translation method, inversion method, inclusion method, interpolation method, restructuring method and comprehensive method. These techniques can be used not only in translation but also in interpretation and should be used more skillfully.

\subsection{Added translation method.}

Refers to adding some words, short sentences or sentences in the translation and according to different ways of thinking, language habits and expressions in English and Chinese express the meaning contained in the original more accurately. This method is mostly used in English to Chinese miles. There are a lot of main sentences in Chinese, while English sentences generally have a subject [5]. Therefore, when translating Chinese without main sentences, most of them are available except for the few ones that can be translated in English without clause, passive voice or "There be ..." structure According to the context to make up the subject, so that the sentence is complete. There are also great differences between English and Chinese in terms of nouns, pronouns, conjunctions, prepositions and articles. In English, pronouns are used more frequently. When it comes to a person's organs and things owned by or belonging to a person, the pronoun pronoun must be added before it. 
Therefore, it is necessary to supplement the main pronouns in the CE translation, but it needs to be cut down according to the situation in the English-Chinese translation. The logical relationship between English words and words, phrases and phrases, and sentences and sentences is generally expressed in conjunctions, while Chinese often expresses this relationship through context and word order [5]. Therefore, often need to add conjunctions in the translation of English. English sentences cannot be separated from prepositions and articles. In addition, in the translation also pay attention to add some of the original implied without explicit words and some general, explanatory words to ensure that the meaning of the translation is complete.

\subsection{Provincial translation.}

This is a translation method corresponding to the method of translating, which is, deleting words that do not conform to the thinking habits, language habits and expressions of the target language to avoid the cumbersome translation [6]. The example of the translation method can be reversed.

\subsection{Conversion method.}

The process of translation in order to make the translation of the target language meet the presentation, methods and habits of the original sentence in the part of speech, sentence patterns and voice and so on. Specifically, in the part of speech, there are nouns into pronouns, adjectives, verbs; the verbs into nouns, adjectives, adverbs, prepositions; the adjectives into adverbs and phrases. In the sentence composition, the subject into adverbial, attributive, object, table language; the predicate into the subject, attributive, form language; the attributive into adverbial, subject; the object into the subject [6]. In the sentence pattern, the parallel sentence into compound sentence, the compound sentence into a parallel sentence, the adverbial clause into attributive clause. In voice, you can turn the active voice into a passive voice.

\subsection{Split sentence and merger law.}

This is the two corresponding translation methods. The disassembly method is to split a long and complex sentence into several shorter and simpler sentences, usually used for English to Chinese translation. The merge method is to combine several short sentences into one long sentence, which is generally used in Chinese-English translation. Chinese emphasizes Italian meaning, the structure is loose, so simple sentences are more; English emphasizes form, the structure is more rigorous, so long sentences are more [6]. Therefore, it is necessary to pay attention to the use of conjunctions, participles, prepositions, infinitives, attributive clauses and independent structures to link Chinese short sentences into longer sentences according to the needs of the Chinese-English translation. In the English-Chinese translation, the relation pronouns, relational adverbs, The main verb connection, parallel or transition joints, follow-up composition and the main connection, and the end of Italy group will be cut off long sentences, translated into Chinese clause. This can basically retain the English language order, Shun translation of the whole sentence, with the modern Chinese short and long sentences, single sentences and complex sentence syntax rhetoric.

\subsection{Positive and negative translation law.}

These two methods are usually used for Chinese to English, and occasionally for English to Chinese. The so-called is the translation, refers to the sentence in accordance with the same language order or manner of expression into English. The so-called anti-translation refers to the sentence in accordance with the Chinese word order or expression contrary to English [7]. Positive translation and anti-translation often have the same effect, but anti-translation tends to be more in line with English thinking and expression habits.

\subsection{Literal translation.}

Literal translation is not word to word death, but according to literal translation, not too much extended and annotated. The use of literal translation can generally retain the original cultural features [7]. For those who have a national image in both languages, or are unique to a particular nation, but vivid metaphor, easy to understand for the interpreter into the reader, then literal 
translation more appropriate.

\subsection{Free translation.}

In some cases, when using literal translation, the reader cannot accept it. At this time, he has to sacrifice some cultural features of the original text and make contextual translation to keep the original content as complete as possible. In a vivid and unacceptable way of expression that is distinctively national in nature, it must be profoundly understood and its spiritual implications translated. At this time, hard translation cannot be carried out verbatim [7]. The following part of the line cannot be literal translation, only to give up its literal meaning and image meaning, reflecting the unique cultural heritage.

\section{Summary}

Cultural differences are particularly prominent in cross-cultural translation activities. We should fully understand the relationship between cultural differences and translation, and make more efforts to understand and translate the cultural background knowledge. Because solving the cultural differences in translation is the key to ensuring translation success. In addition, cultural sensitivity has become an indispensable requirement for a qualified translator.

\section{References}

[1] W.Zh. Hu, Cultural Differences and Foreign Language Teaching, Foreign Language Teaching and Research, 2002, pp.41-45.

[2] W. Zh. Wu, The communication between different cultures and foreign language teaching, Foreign language teaching and research, 2015, vol. 4, pp. 23-27.

[3] Y.L. Jia, On the Chinese translation studies Characteristics, Chinese translation, 2011, pp.12-16.

[4] H.Q. Hu, Learn Chinese translation must be established on the one hundred contemporary translation, Chongqing University Press, 2014, pp.16-21.

[5] L.N. Xu, Chinese translation skills reflection and review, China Science and Technology Translation, 2008, pp.34-37.

[6] Intercultural Communication and English Learning, Shanghai: Shanghai Translation Publishing House, 2008, pp55-58.

[7] T.X. Chu and H.H. Zhang, The current situation of Chinese translation theory, Translation theory of our country, 2012, pp.23-27. 